\section{MALIGNANT CHOLERA.}

BLFFDING-COLD SALT AND WATER IN GALLONS.-MERCURIAL FRICTIONS, \&c.

Is reply to the request of the Central Board of Health, for a short account of the treatment of cholera, I beg to state that bleeding was found to be most beneficial in all cases, where I was called sufficiently early to adopt it, that is, before the stage of collupse, and that it was decidedly injurious after.

In real cases of what is called cholera, where there was vomiting of watery fuid like cold chicken broth, and evacuations of the very same appearance, neither feculent or bilious, after bleeding, an ounce of muriate of soda in a tumbler of hot water, as an emetic, then a teaspoonful of salt in a tumbler of cold water, to be drunk as often and as freely as the patient chooses, with the saline effervescents, lime-water and milk, and toast-and-water; a solution of isinglass per anum, frequently, with 20 or 50 drops tr. opii in it. It is astonishing how much toast and water and cold salt and water was taken by some of them; three or four gallons in a night were taken and rejected; but I found those who drank most salt and water began to have a yellowish tinge of bile in the evacuations sooner than the others. I thought the lime-water, two parts, with one part boiled milk, mixed, did good, particularly with children; in all these cases the liniment. hydrarg. fort. was well and assiduously rubbed in ; and where the mouth was quickly made sore, they generally began to mend rapidly. In the stage of collapse I found blankets, flannel bandages, bottles of hot water, flat bags of bot salt, friction, counter extension where there was spasmodic contraction, and free ventilation, of great use; the-mercurial friction was kept up, the salt-and-water and toast-andwater were continued; isinglass in solution, with a little brandy and tr. opii, was injected, and cataplasms of mustard and spt. terebinth. were applied all along the spine, over the chest and abdomen, and to the feet; but $I$ did not think any external application of much use in this state.

In a few cases of bilious diarrhcea, I gave the nitrous acid mixture, with tr. opii, as recommended by Dr. Hope of Chatham; I thought it did good, but in cases of real cholera it entirely failed with me. Opium, brandy, cajeput oil, and all stimulants, hurried on the blue stage; calomel did no good. The disease should be called "spasmodic asphyxia."

Willitam Collyns, M.R.C.S. Kentor, near Exeter, Oct. 3rd, 1832. No. 477 .

\section{LETTER FROM DR. GILLKREST}

RESPECTING SOME STATEMENTS IN TUE

PAPER OF MR. ORTON,

$$
\text { At Page 43, No. } 475 \text {. }
$$

\section{To the Editor of The Lancet.}

Sir,-In the number of your journal for the 6th inst, there is a letter from Mr. Orton, in which reference is made to me in respect to a person who died of cholera in the Military Cholera Hospital, in Regentstreet, Vauxhall-road, the man baving first felt unwell, as is stated, while rubbing a cholera patient. Most disagreeable indeed it is to me, when thus calied upon by a gentleman with whom I have always been on the best terms, to be obliged to say that I felt perfectly astounded by the manner in which the circumstances connected with the above case have been sent forth to the public ; and your readers will probably not be less astonished than I have been, when they peruse the following statement.

On the 6th of August last, I was informed that a case, incontestably proving the contagious nature of cholera, had at last occurred under Mr. Orton, as his steward, or hospital-sergeant, had been attacked with the disease immediately after rubbing a patient. Well aware, from long experience, of the necessity of inquiring into such matters a little more closely, I gladly availed myself of the permission of $\mathrm{Mr}$. Orton, whom I saw immediately after, to accompany him to his hospital, a distance of about a mile and a half. On setting out, Mr. Orton said that " as it was but fair to state both sides of a question," he must admit that the man, contrary to his usual babits, had been drinking beer,-a circumstance which I observe has been forgotten by $\mathrm{Mr}_{\text {r }}$ Orton in his letter, though considered at the time, it would appear, as of importance. enough to be noticed ; for who will deny: importance even to trifling deviations froms the usual mode of living, during an epidemic. influence? Indeed I feel warranted in concluding that Mr. Orton's details bear strong; marks of having been hastily drawn up; for otherwise, I am sure, from my knowledge of this gentleman, that another cirn cumstance, perhaps of still more importan'ie, would not have been omitted,- - the ag $a$ of the man, which was sixty-five. I cert'dinly expected that, on my arrival at the hos,pital, I should bave found a stout sergear at of a regiment labouring under an attack, and I was not a little surprised to find that our patient was a worn-out Chelsea pansioner, who, though at forlorn hopes enough in his day, had still, it appeared, gallantry enough left not to object to the contagionists' for 